\title{
Retraction Note: Analysis of the social capital indicators by using DEMATEL approach: the case of Islamic Azad University
}

\author{
Davood Kiakojuri ${ }^{1} \cdot$ Shahaboddin Shamshirband ${ }^{2,3} \cdot$ Nor Badrul Anuar $^{3}$. \\ Johari Abdullah ${ }^{4}$
}

Published online: 9 November 2019

(c) Springer Nature B.V. 2019

\section{Retraction Note: Qual Quant (2015) 49:1985-1995 https://doi. org/10.1007/s11135-014-0085-9}

The Editor-in-Chief has retracted this article (Kiakojuri et al. 2015) because validity of the content of this article cannot be verified. This article showed evidence of peer review and authorship manipulation. Authors Davood Kiakojuri, Shahaboddin Shamshirband and Nor Badrul Anuar do not agree to this retraction. Author Johari Abdullah has not responded to any correspondence from the editor or publisher about this retraction.

\section{Reference}

Kiakojuri, D., Shamshirband, S., Anuar, N.B., Abdullah, J.: Analysis of the social capital indicators by using DEMATEL approach: the case of Islamic Azad University. Qual. Quant. 49, 1985-1995 (2015)

The original article can be found online at https://doi.org/10.1007/s11135-014-0085-9.

Davood Kiakojuri

davoodkia@gmail.com

Shahaboddin Shamshirband

shamshirband1396@gmail.com

Nor Badrul Anuar

askbard@gmail.com

Johari Abdullah

johari.abdullah@gmail.com

1 Department of Public Administration, Chalous Branch Islamic Azad University, Chalous, Iran

2 Department of Computer Science, Chalous Branch, Islamic Azad University (IAU), 46615-397 Chalous, Mazandaran, Iran

3 Department of Computer System and Technology, Faculty of Computer Science and Information Technology, University of Malaya, 50603 Kuala Lumpur, Malaysia

4 Faculty of Computer Science and Information Technology, Universiti Malaysia Sarawak, 94300 Kota Samarahan, Sarawak, Malaysia 
Publisher's Note Springer Nature remains neutral with regard to jurisdictional claims in published maps and institutional affiliations. 